(c) American Dairy Science Association, 2004.

\title{
Genetic Susceptibility to Neospora caninum Infection in Holstein Cattle in Ontario
}

\author{
Y. Pan, ${ }^{1}$ G. B. Jansen, ${ }^{1}$ T. F. Duffield, ${ }^{2}$ S. Hietala, ${ }^{3}$ D. Kelton, ${ }^{2}$ \\ C. Y. Lin, ${ }^{1,4}$ and A. S. Peregrine ${ }^{5}$ \\ ${ }^{1}$ CGIL, Department of Animal and Poultry Science, \\ University of Guelph, Ontario, Canada N1G 2W1 \\ ${ }^{2}$ Department of Population Medicine, \\ University of Guelph, Ontario, Canada N1G 2W1 \\ ${ }^{3}$ California Animal Health \& Food Safety Laboratory System, \\ University of California, Davis 95616 \\ ${ }^{4}$ Dairy and Swine Research and Development Centre, \\ Agriculture and Agri-Food Canada, Lennoxville, \\ Quebec, Canada J1M 1 Z3 \\ ${ }^{5}$ Department of Pathobiology, University of Guelph, \\ Ontario, Canada N1G 2W1
}

\begin{abstract}
Neospora caninum has been reported to be an important cause of endemic fetal loss and occasional abortion epidemics in cattle around the world. This study examined 12,016 sera collected from 9723 Holstein cows on 125 herds across Ontario in 1998, 1999, and 2000. An enzyme-linked immunosorbent assay was used to examine the sera for antibodies to $N$. caninum. The overall prevalence of $N$. caninum antibodies in the cattle was $11.2 \%$ and the prevalence in individual herds varied from 0 to $70.4 \%$. Among 3109 daughter-dam pairs, 619 positive dams had 252 positive daughters, giving a detected vertical transmission rate of $40.7 \%$. In contrast, there were only $6.7 \%$ positive daughters from negative dams (167 of 2490). Pedigree edits left 8031 cows with 1463 sires for estimation of heritability. Five genetic models (sire model, animal model, siredam model, a sire-maternal grandsire model, and a maternal effects model) with fixed effects of bleeding year-month, age of the animals, and herd were fitted to the data. The estimated heritability of susceptibility to $N$. caninum ranged between 0.084 and 0.124 . The sire-maternal grandsire model and the maternal effects model provided better fit than the other models because the maternal genetic variance was much greater than the direct genetic variance. To reduce the incidence of $N$. caninum infection, more emphasis should be placed on management practices than on genetic selection.
\end{abstract}

(Key words: Neospora caninum, genetic susceptibility, dairy cattle)

Received July 3, 2003.

Accepted July 21, 2004.

Corresponding author: A. S. Peregrine; e-mail: aperegri@ovc. uoguelph.ca.
Abbreviation key: AIC = Akaike information criterion, $\mathbf{A M}=$ animal model, $\mathbf{A M M}=$ animal maternal effects model, $\mathbf{M S E}=$ mean square error, SDM = siredam model, SGM = sire-maternal grandsire model, $\mathbf{S M}=$ sire model, $\mathbf{S} / \mathbf{P}=$ sample-to-positive.

\section{INTRODUCTION}

Neospora caninum is a protozoan parasite that was first identified in dogs (Dubey et al., 1988) and has subsequently been found to be an important cause of endemic fetal loss, and occasional abortion epidemics, in dairy cattle (Anderson et al., 1991). In Australia, Boulton et al. (1995) examined 729 aborted bovine fetuses and reported that 152 were associated with $N$. caninum, i.e., an attributable fraction of $21 \%$. In Californian dairy cattle, Anderson et al. (1995) attributed $42.5 \%$ of examined aborted fetuses (113 of 266) to $N$. caninum and concluded that this parasite was the major cause of abortion. Currently, N. caninum is the single most common infectious cause of abortion diagnosed in Ontario cattle, as $15 \%$ of all bovine abortion submissions to the Animal Health Laboratory, University of Guelph, are associated with this parasite (McEwen et al., 2001).

Not all cattle that are seropositive for $N$. caninum have an abortion. However, the risk of abortion for seropositive cows has been shown to be twice that for seronegative cows on a dairy herd in central California (Paré et al., 1997). Similarly, Atkinson et al. (2000) showed that the abortion rate was 26\% (18 of 68) for $N$. caninum-seropositive cows but only $3 \%$ (3 of 117) for seronegative cows on a commercial dairy herd in Australia. In general, it appears that $N$. caninum-seropositive cattle are 3 to 4 times more likely to abort than seronegative animals (Paré et al., 1997; Moen et al., 1998; Corbellini et al., 2002). 
Abortion in cattle attributable to fetal infection with $N$. caninum is now recognized in many countries ( $\mathrm{Du}-$ bey and Lindsay, 1996) and generally occurs between 3 and 7 mo of gestation. Aside from the economic cost of failed reproduction, $N$. caninum infection can also cause indirect economic losses as a result of premature culling and diminished milk production. For example, seropositive cows in their first lactation on a 2000-head farm in California had a greater risk of being culled (1.6 times) and produced less milk (2.5 lb/d per cow) than seronegative cows (Thurmond and Hietala, 1996, 1997). Thus, $N$. caninum may have a significant impact on the profitability of dairy cattle.

Most research indicates that vertical transmission is the primary route by which cattle become infected with $N$. caninum. Thus, in seroepidemiological studies on 2 dairies in the San Joaquin Valley, California, 81\% of seropositive cows (93 of 115) and 5\% of seronegative cows (8 of 170) had congenitally infected calves (Paré et al., 1996). Similarly, Davison et al. (1999) in the United Kingdom concluded that the efficiency of vertical transmission was $95.2 \%$ (118 seropositive calves out of 124 offspring from seropositive dams). Finally, research on the rate of vertical transmission of $N$. caninum for 23 dairy herds in Québec indicated that while the prevalence of seropositive animals in herds varied from 4.3 to $61.8 \%$ (average $=21.9 \%$ ), the overall rate of vertical transmission was $44.4 \%$, varying from 0 to $85.7 \%$ within herds (Bergeron et al., 2000).

The high rate of vertical transmission of $N$. caninum has led to the recommendation to cull infected animals as the primary strategy to reduce their number in a herd. However, for herds with a high prevalence, culling all infected animals within a short period of time is not a practical way to eliminate $N$. caninum from a herd. Thus, to enable the dairy industry to develop optimal management strategies for limiting or reducing the impact of $N$. caninum infections, a large study was undertaken on dairy farms in Ontario. Serum samples were collected from Holstein cattle across the province, and an ELISA was used to determine the $N$. caninum antibody status of each sample. The objectives of this study were to use the resultant data to determine the prevalence of $N$. caninum in Ontario cattle, to estimate the efficiency of vertical transmission of the parasite, and to investigate the scope for genetic strategies to reduce the prevalence of $N$. caninum infections by estimating heritability under several genetic models.

\section{MATERIALS AND METHODS}

\section{Collection and Analysis of Sera}

Blood samples were collected from Ontario dairy herds in 1998, 1999, and 2000. Herds that were bled in $1998(\mathrm{n}=56)$ belonged to the Ontario Sentinel Herd Project (Cramer et al., 2002) and were intentionally selected for a study on udder health. These herds were considered representative of Ontario Holstein herds. Herds that were bled in $1999(n=86)$ were selected for a case-control study; 28 herds had had at least one abortion in the previous year that was diagnosed as due to $N$. caninum on the basis of fetal histopathology; 30 herds had had at least one abortion in the previous year that was diagnosed as not due to $N$. caninum on the basis of fetal histopathology; and 28 herds were selected on the basis of having a herd $N$. caninum seroprevalence that was less than $7 \%$. Herds bled in 2000 $(\mathrm{n}=50)$ were selected from the pool of herds previously sampled on the basis of a $N$. caninum seroprevalence that was $\geq 10 \%$ in 1998 or 1999 . Blood samples were collected only from lactating cows in the herds visited in 1998. However, for the herds visited in 1999 and 2000 , samples were collected from adult cows and heifers greater than 6 mo of age. The 1998 and 1999 data were used to identify seropositive cows and existing daughters. The 2000 data were collected primarily to identify more daughters of the seropositive cows previously identified in 1998 and 1999. Thus, if seropositive dams were culled prior to the herd visit in 2000 , information about their daughters would still have been used. Previous work with the same $N$. caninum serology data as used in this study has indicated that among all the herds, as a whole, the risk of cattle being culled was not associated with their $N$. caninum serostatus (Cramer et al., 2002; Hobson, 2003). Sera were prepared from all blood samples within $24 \mathrm{~h}$ of collection and stored at $-70^{\circ} \mathrm{C}$ prior to analysis.

All sera were assayed for antibodies to $N$. caninum using a kinetic-ELISA at the California Animal Health \& Food Safety Laboratory System, University of California, Davis (Paré et al., 1995). A sample-topositive ( $\mathbf{S} / \mathbf{P}$ ) control $\mathrm{V}_{\max }$ (average maximum slope of the optical density over time) ratio of $\geq 0.45$ was used to maximize the percentage correct classification of $N$. caninum-infection status, with an estimated sensitivity of $88.6 \%$ and specificity of $96.5 \%$. Thus, for most analyses the cows were considered seropositive when the ELISA S/P ratios were $\geq 0.45$ and seronegative when the $\mathrm{S} / \mathrm{P}$ ratios were $<0.45$. For seroconversion analyses, $\mathrm{S} / \mathrm{P}$ ratios in the range $\geq 0.45$ to $<0.70$ were defined as moderately positive, while values $\geq 0.70$ were defined as strongly positive. At the $\mathrm{S} / \mathrm{P}$ ratio $\geq 0.70$, the sensitivity and specificity of the antibody ELISA are 79 and $100 \%$, respectively (Paré et al., 1995).

A total of 12,016 serum samples were analyzed. Cows with repeated samples included 811 sampled in 1998 and 1999, 1141 sampled in 1999 and 2000, and 413 sampled in 1998 and 2000. These repeated records were 


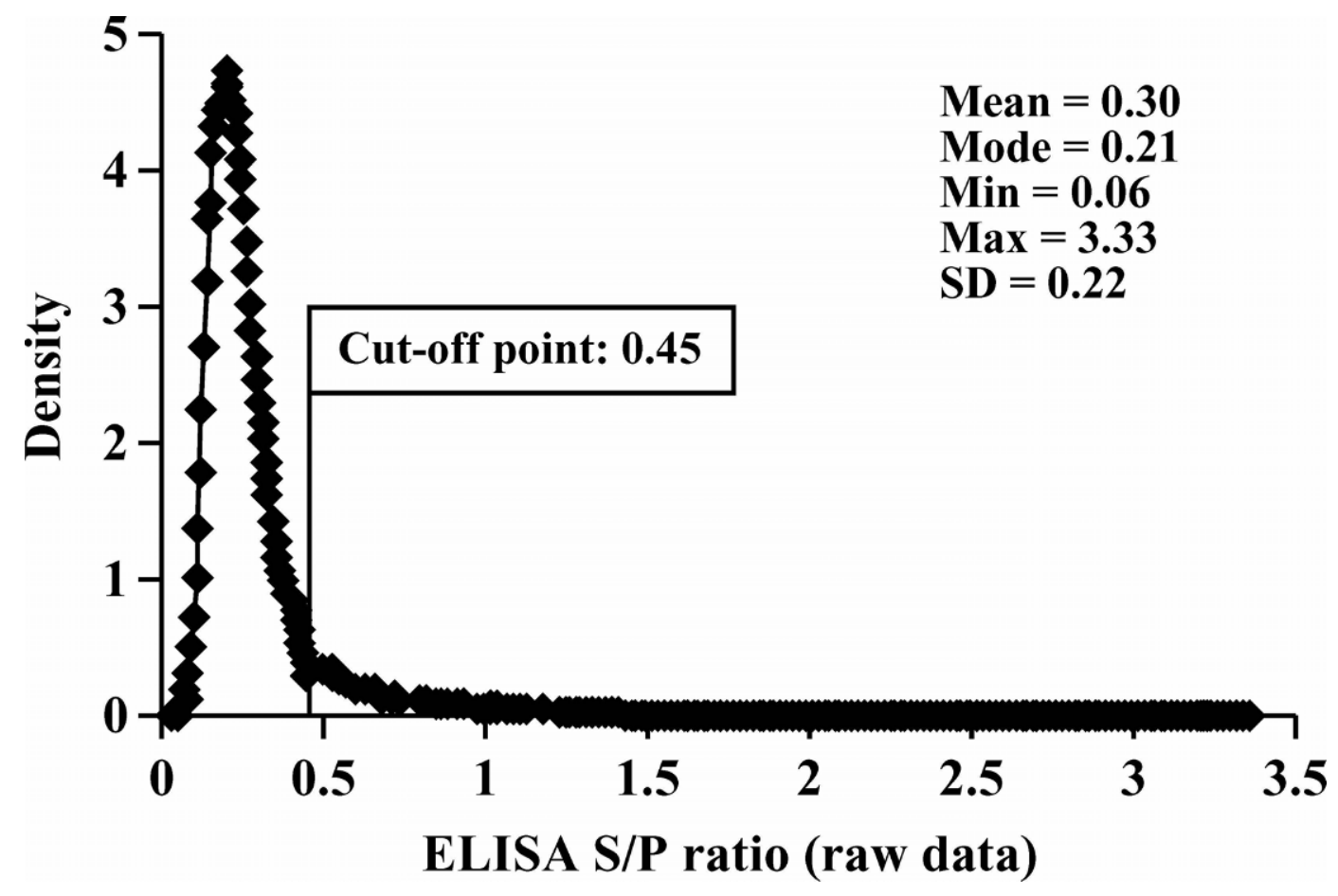

Figure 1. Density distribution of Neospora caninum antibody ELISA S/P (sample-to-positive) ratios before logarithmic transformation.

used to compute the conversion rates between seropositive and seronegative status. Further analyses included only the record with the highest $\mathrm{S} / \mathrm{P}$ ratio for cows with multiple records, leaving 9723 samples. These unique serum samples collected over the 3 yr included 3109 daughter-dam pairs; these were used to estimate the efficiency of vertical transmission. The analysis of heritability included 8031 cows and heifers whose sire, dam, and maternal grandsire were traceable in the pedigree file provided by the Canadian Dairy Network, Guelph, Ontario.

The raw ELISA S/P ratios were distributed with a long tail on the right (Figure 1). A logarithmic transformation by the formula $\ln (\mathrm{Y})+4.5$ yielded transformed data whose distribution was much closer to normal (Figure 2).

\section{Definitions of Prevalence, Vertical Transmission, and Seroconversion}

The prevalence of seropositive animals ( $\mathrm{S} / \mathrm{P}$ ratio $\geq 0.45$ ) in herds was defined as the number of seropositive animals divided by the total number of animals tested within that herd in a given year. The horizontal transmission rate was defined as the proportion of seropositive daughters born to seronegative dams. The efficiency of vertical transmission was estimated as the proportion of seropositive daughters born to seroposi- tive dams. For calculation of both transmission parameters, the serostatus of the dam in each dam-daughter pair was defined on the basis of serological data that were obtained for the dam prior to the birth of the daughter; the dam was defined as $N$. caninum seropositive if it tested positive on one or more occasions; the dam was defined as $N$. caninum seronegative if all serum samples tested negative. Similarly, a daughter was defined as $N$. caninum seropositive if one or more serum samples collected from the animal tested positive.

A cow was considered to have seroconverted if the animal was seropositive in one year but seronegative in the previous year, or vice versa. The seropositive conversion rate was calculated by dividing the number of seropositive animals in a given year that converted from seronegative in the previous year by the total number of seronegative animals in the previous year. The seronegative conversion rate was obtained by dividing the number of seronegative animals in a given year that converted from seropositive in the previous year by the total number of seropositive animals in the previous year. A paired $t$-test was used to analyze the seroconversion data.

\section{Genetic Models}

The following models were used to estimate the heritability of susceptibility to $N$. caninum infection. 


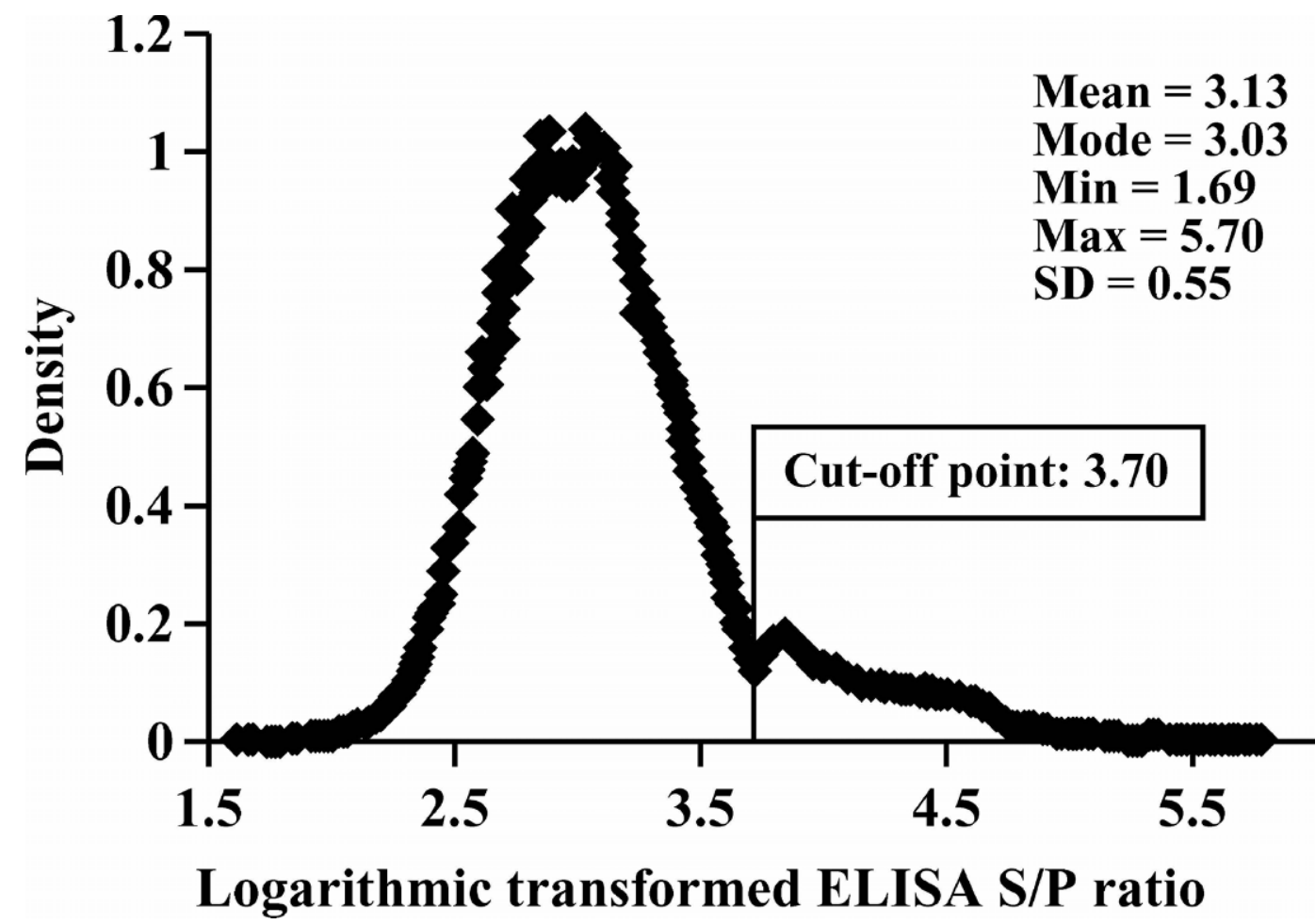

Figure 2. Density distribution of Neospora caninum antibody ELISA S/P (sample-to-positive) ratios after logarithmic transformation.

Sire model (SM): $\mathbf{y}=\mathbf{X}_{\mathrm{s}} \boldsymbol{\beta}_{\mathrm{s}}+\mathbf{b}_{\mathrm{h}} \mathbf{c}+\mathbf{Z}_{\mathrm{s}} \mathbf{s}+\mathbf{e}$

Animal model (AM): $\mathbf{y}=\mathbf{X} \boldsymbol{\beta}+\mathbf{Z}_{\mathrm{a}} \mathbf{a}+\mathbf{e}$

Sire-maternal grandsire model (SGM):

$$
\mathbf{y}=\mathbf{X} \boldsymbol{\beta}+\mathbf{Z}_{\mathrm{s}} \mathbf{s}+\mathbf{Z}_{\mathrm{g}} \mathbf{g}+\mathbf{e}
$$

Sire-dam model (SDM):

$$
\mathbf{y}=\mathbf{X} \boldsymbol{\beta}+\mathbf{Z}_{\mathrm{s}} \mathbf{s}+\mathbf{Z}_{\mathrm{m}} \mathbf{m}+\mathbf{e}
$$

Animal maternal effect model (AMM):

$$
\mathbf{y}=\mathbf{X} \boldsymbol{\beta}+\mathbf{Z}_{\mathrm{a}} \mathbf{a}+\mathbf{Z}_{\mathrm{m}} \mathbf{m}+\mathbf{e}
$$

where

$\mathbf{y}=$ vector of the transformed ELISA antibody data, or the categorical infection status (sire model only);

$\boldsymbol{\beta}=$ vector of fixed effects of bleeding year-month, age (yr), and herd;

$\boldsymbol{\beta}_{\mathrm{S}}=$ vector of fixed effects of bleeding year-month and age (yr);

$\mathbf{b}_{\mathrm{h}}=$ regression coefficients of $\mathrm{y}$ on the herd seroprevalence;

$\mathbf{c}=$ vector of herd seroprevalence over the $3 \mathrm{yr}$;

$\mathbf{s}=$ vector of sire effects;

$\mathbf{a}=$ vector of direct additive genetic effects; $\mathbf{g}=$ vector of maternal grandsire effects;

$\mathbf{m}=$ vector of maternal genetic effects; and

$\mathbf{e}=$ vector of random residual effects.

[3] The matrices $\mathbf{X}_{\mathrm{s}}, \mathbf{X}, \mathbf{Z}_{\mathrm{a}}, \mathbf{Z}_{\mathrm{s}}, \mathbf{Z}_{\mathrm{m}}$, and $\mathbf{Z}_{\mathrm{g}}$ are known incidence matrices that relate observations to their respective fixed and random effects. The variances and covariances for the random effects were $\mathrm{V}(\mathbf{s})=\mathbf{A} \sigma_{\mathrm{s}}^{2}$, $\mathrm{V}(\mathbf{g})=\mathbf{A} \sigma_{\mathrm{g}}^{2}, \mathrm{~V}(\mathbf{a})=\mathbf{A} \sigma_{\mathrm{a}}^{2}, \mathrm{~V}(\mathbf{m})=\mathbf{A} \sigma_{\mathrm{m}}^{2}, \operatorname{Cov}(\mathbf{a}, \mathbf{m})=\mathbf{A} \sigma_{\mathrm{am}}$, and $\mathrm{V}(\mathbf{e})=\mathbf{I} \sigma^{2}$ e, where $\mathbf{A}$ is the numerator relationship matrix between animals and $\mathbf{I}$ is the identity matrix. The variance components and computation of heritability in different models is shown in Table 1. The direct, maternal, and total heritability in the animal maternal effect model (AMM) were defined as $\mathrm{h}_{\mathrm{d}}^{2}=\sigma_{\mathrm{a}}^{2} / \sigma_{\mathrm{p}}^{2}, \mathrm{~h}_{\mathrm{m}}^{2}=$ $\sigma_{\mathrm{m}}^{2} / \sigma_{\mathrm{p}}^{2}$ and $\mathrm{h}_{\mathrm{T}}^{2}=\left(\sigma_{\mathrm{a}}^{2}+1.5 \sigma_{\mathrm{am}}+0.5 \sigma_{\mathrm{m}}^{2}\right) / \sigma_{\mathrm{p}}^{2}$, respectively, where $\sigma_{\mathrm{p}}^{2}=\sigma_{\mathrm{a}}^{2}+\sigma_{\mathrm{am}}+\sigma_{\mathrm{m}}^{2}+\sigma_{\mathrm{e}}^{2}$ (Willham, 1972).

All 5 models were fitted using ASREML (Gilmour et al., 2001). The SAS GLM, VARCOMP, and MIXED procedures (SAS, 1990) were also used in the analysis of the variation of susceptibility to $N$. caninum infection. The categorical analysis of serological status (i.e., seropositive or seronegative as defined with the ELISA $\mathrm{S} / \mathrm{P}$ threshold of $\geq 0.45$ ) with the sire model was fitted by ASREML using a probit link function (the cumulative normal distribution function) with the residual vari- 
Table 1. The variance components and calculation of heritability with different models. ${ }^{1}$

\begin{tabular}{lll}
\hline Model & $\begin{array}{l}\text { Variance } \\
\text { component }\end{array}$ & Heritability \\
\hline Sire model & $\sigma_{\mathrm{s}}^{2}, \sigma_{\mathrm{e}}^{2}$ & $4 \sigma_{\mathrm{s}}^{2} /\left(\sigma_{\mathrm{s}}^{2}+\sigma_{\mathrm{e}}^{2}\right)$ \\
Animal model & $\sigma_{\mathrm{a}}^{2}, \sigma_{\mathrm{e}}^{2}$ & $\sigma_{\mathrm{a}}^{2} /\left(\sigma_{\mathrm{a}}^{2}+\sigma_{\mathrm{e}}^{2}\right)$ \\
Sire-maternal grandsire model & $\sigma_{\mathrm{s}}^{2}, \sigma_{\mathrm{g}}^{2}, \sigma_{\mathrm{e}}^{2}$ & $4 \sigma_{\mathrm{s}}^{2} /\left(\sigma_{\mathrm{s}}^{2}+\sigma_{\mathrm{g}}^{2}+\sigma_{\mathrm{e}}^{2}\right)$ \\
Sire-dam model & $\sigma_{\mathrm{s}}^{2}, \sigma_{\mathrm{m}}^{2}, \sigma_{\mathrm{e}}^{2}$ & $4 \sigma_{\mathrm{s}}^{2} /\left(\sigma_{\mathrm{s}}^{2}+\sigma_{\mathrm{m}}^{2}+\sigma_{\mathrm{e}}^{2}\right)$ \\
Animal maternal effect model & $\sigma_{\mathrm{a}}^{2}, \sigma_{\mathrm{am}}, \sigma_{\mathrm{m}}^{2}, \sigma_{\mathrm{e}}^{2}$ & $\left(\sigma_{\mathrm{a}}^{2}+1.5 \sigma_{\mathrm{am}}+0.5 \sigma_{\mathrm{m}}^{2}\right) /\left(\sigma_{\mathrm{a}}^{2}+\sigma_{\mathrm{am}}+\sigma_{\mathrm{m}}^{2}+\sigma_{\mathrm{e}}^{2}\right)$ \\
\hline
\end{tabular}

${ }^{1} \sigma_{\mathrm{s}}^{2}=$ Sire genetic variance, $\sigma_{\mathrm{g}}^{2}=$ maternal grandsire genetic variance, $\sigma_{\mathrm{a}}^{2}=$ direct additive genetic variance, $\sigma_{\mathrm{m}}^{2}=$ maternal genetic variance, $\sigma_{\mathrm{am}}=$ genetic covariance between direct and maternal effects, and $\sigma_{\mathrm{e}}^{2}=$ residual variance.

ance set to 1 . All remaining analyses of variance components used the log transformed ELISA S/P ratio directly.

The fit of the models to the complete data set was compared by mean squared error (MSE) and Akaike information criterion (AIC, Akaike, 1973). The MSE using the complete data set was computed as

$$
\mathrm{MSE}_{\mathrm{c}}=\frac{1}{\mathrm{n}} \sum_{\mathrm{i}=1}^{\mathrm{n}}\left(\mathrm{y}_{\mathrm{i}}-\hat{\mathrm{y}}_{\mathrm{i}}\right)^{2}
$$

where $\mathrm{y}_{\mathrm{i}}=$ observed value, $\hat{\mathrm{y}}_{\mathrm{i}}=$ predicted value by a given model, and $\mathrm{n}=$ total number of observations in the data set (8031). The AIC was obtained by $n \times \ln (\mathrm{SSR} /$ n) $+2 \times(p+1)$, where SSR is the sum of squares of residuals, and $p$ is the number of parameters in the model.

The models were also validated by randomly splitting the data into 2 parts (e.g., Varona et al., 1999): a retained part, consisting of $70 \%$ of the records, for parameter estimation, and a deleted part, consisting of the remaining $30 \%$ of the records, for measuring predictive ability. Random effects for all animals were kept in the analysis of the retained records to obtain the solutions needed to predict the deleted records. The predictive ability of the 5 models was compared by

$$
\operatorname{MSE}_{\mathrm{d}}=\frac{1}{\mathrm{~N}_{\mathrm{d}}} \sum_{\mathrm{i}=1}^{\mathrm{N}_{\mathrm{d}}}\left(\mathrm{y}_{\mathrm{i}}-\hat{\mathrm{y}}_{\mathrm{i}}^{*}\right)^{2}
$$

where $y_{i}=$ observed value of a deleted record, $\hat{y}_{i}^{*}=$ predicted value of a deleted record using the solutions for a given model from the retained records, and $\mathrm{N}_{\mathrm{d}}=$ number of deleted records.

\section{RESULTS AND DISCUSSION}

\section{Seroprevalence Estimation}

The overall prevalence of antibody to $N$. caninum in the 125 selected Holstein herds was $11.2 \%$. The average herd seroprevalences were estimated at 10.8, 11.3, and $13.5 \%$ in 1998, 1999, and 2000, respectively (Table 2). The average herd seroprevalence in 2000 was higher than in the previous 2 yr because only herds with a $N$. caninum seroprevalence of $10 \%$ or greater in 1998 or 1999 were revisited in 2000.

\section{Serological Conversion}

On the basis of the ELISA S/P threshold of $\geq 0.45$, the seropositive conversion rate was $3.98 \%$ of 778 cows between 1998 and 1999, 5.08\% of 886 cows between 1999 and 2000, and $7.71 \%$ of 350 cows between 1998 and 2000 (Table 3). The seropositive conversion is examined in more detail in Tables 4 to 6 . There were 27 animals (of 778) that converted from seronegative in 1998 to moderately seropositive in 1999, and 4 animals (of 778) that converted from seronegative in 1998 to strongly seropositive in 1999 . Table 5 shows that there were 31 animals (of 886) that converted from seronegative in 1999 to moderately positive in 2000 , and 14 animals (of 886) that converted from seronegative in

Table 2. Neospora caninum seroprevalence in the selected Holstein herds (125) across Ontario in the years 1998, 1999, and $2000 .^{1}$

\begin{tabular}{lccc}
\hline & 1998 & 1999 & 2000 \\
\hline Herds (no.) & 56 & 86 & 50 \\
Seroprevalence (\%) & 10.8 & 11.3 & 13.5 \\
Variation (\%) & $0-66.7$ & $0-70.4$ & $0-64.2$ \\
Total animals (no.) & 3334 & 4487 & 4195 \\
\hline
\end{tabular}

${ }^{1}$ Overall herd average over the 3 yr was $11.2 \%$. 
Table 3. Seroconversion rate between seropositive and seronegative cows using an ELISA S/P (sample-topositive) threshold of $\geq 0.45$ when the animals had repeated records in the years 1998, 1999, and 2000 .

\begin{tabular}{lccc}
\hline Period & $1998-1999^{1}$ & $1999-2000^{1}$ & $1998-2000^{1}$ \\
\hline Seropositive conversion (\%) & 3.98 & 5.08 & 7.71 \\
$\longrightarrow+$ & $(778)^{2}$ & $(886)^{2}$ & $(350)^{2}$ \\
& & & \\
Seronegative conversion (\%) & 42.42 & 28.24 & 65.43 \\
$+\longrightarrow$ & $(33)^{3}$ & $(255)^{3}$ & $(81)^{3}$ \\
Total samples (no.) & 811 & 1141 & 431 \\
\hline
\end{tabular}

${ }^{1}$ There was a significant difference for the ELISA S/P ratio of animals between the $2 \mathrm{yr}$ tested by a paired $t$-test $(P<0.001)$.

${ }^{2}$ The number in parentheses denotes the number of seronegative animals in the first year.

${ }^{3}$ The number in parentheses denotes the number of seropositive animals in the first year.

1999 to strongly positive in 2000 . Finally, Table 6 indicates that there were 25 animals (of 350 ) that converted from seronegative in 1998 to moderately positive in 2000 , and only 2 animals (of 350) that converted from seronegative in 1998 to strongly positive in 2000 .

Using the ELISA S/P threshold of $\geq 0.45$, the seronegative conversion rate was $42 \%$ of 33 cows between 1998 and 1999, 28.2\% of 255 cows between 1999 and 2000, and $65 \%$ of 81 cows between 1998 and 2000 (Table $3)$. Paired $t$-tests indicated that the changes for these animals were all significant $(P<0.001)$. The seronegative conversion rates between 1998 and 1999 and between 1998 and 2000 were remarkably high. However, about $78 \%$ of the conversion for these 2 periods was from moderately positive to seronegative. Detailed information on seronegative conversion is given in Tables 4,5 , and 6 .

In summary, there was a general tendency over time for seropositive cattle to undergo seronegative conversion, rather than vice versa, which is consistent with data from Canadian cow-calf herds (Waldner et al., 2001)

\section{Vertical Transmission of $\boldsymbol{N}$. caninum Infection}

Among the collected ELISA data, 3109 daughter-dam pairs from 117 herds (1 to 151 dam-daughter pairs per

Table 4. Conversion of serological status among the 3 ELISA S/P (sample-to-positive) categories when the cows had repeated records in the years 1998 and $1999 .{ }^{1}$

\begin{tabular}{lrrrr}
\hline & \multicolumn{4}{c}{1999} \\
\cline { 2 - 4 } 1998 & - & + & ++ & Total \\
\hline- & 747 & 27 & 4 & 778 \\
+ & 11 & 4 & 5 & 20 \\
++ & 3 & 0 & 10 & 13 \\
Total & 761 & 31 & 19 & 811 \\
\hline
\end{tabular}

${ }^{1}$ Categories were classified in terms of the ELISA S/P ratio. Category: $-($ seronegative $)=\mathrm{S} / \mathrm{P}$ ratio $<0.45,+($ moderately seropositive $)=$ $\mathrm{S} / \mathrm{P}$ ratio $\geq 0.45$ and $<0.70$, and ++ (strongly seropositive) $=\mathrm{S} / \mathrm{P}$ ratio $\geq 0.70$. herd) were available to estimate the efficiency of vertical transmission of $N$. caninum. The seroprevalence of $N$. caninum for the 3109 daughters was $13.5 \%$. Among the 3109 daughter-dam pairs, 619 seropositive dams had 252 seropositive daughters, which resulted in an overall detected vertical transmission rate of $40.7 \%$. In contrast, there were only 167 seropositive daughters from 2490 seronegative dams, which gave a detected horizontal transmission rate of $6.7 \%$ (Table 7). Interestingly, the estimate for the rate of vertical transmission increased to only $45 \%$ when the ELISA S/P threshold was raised from $\geq 0.45$ to $\geq 0.70$ (Table 7).

The vertical transmission rate obtained in this study was considerably lower than the estimates of 81 (Paré et al., 1996), 94 (Waldner et al., 2001), and 95.2\% (Davison et al., 1999) obtained from work in California, Alberta (Canada), and the United Kingdom, respectively. However, it was similar to an overall herd estimate of $44 \%$ reported for Québec (Bergeron et al., 2000) and 39 to $43 \%$ for a herd in the USA (Dyer et al., 2000). The discrepancy between these 2 sets of studies is probably due to the fact that the blood samples in the latter reports, as described here, were all collected from animals over 6 mo of age. In contrast, Paré et al. (1996), Waldner et al. (2001), and Davison et al. (1999) used precolostral blood samples. Thus, because of the man-

Table 5. Conversion of serological status among the 3 ELISA S/P (sample-to-positive) categories when the cows had repeated records in the years 1999 and $2000 .^{1}$

\begin{tabular}{lrlrr}
\hline & \multicolumn{4}{c}{2000} \\
\cline { 2 - 4 } 1999 & - & + & ++ & Total \\
\hline- & 841 & 31 & 14 & 886 \\
+ & 58 & 25 & 24 & 107 \\
++ & 14 & 26 & 108 & 148 \\
Total & 913 & 82 & 146 & 1141 \\
\hline
\end{tabular}

${ }^{1}$ Categories were classified in terms of the ELISA S/P ratio. Category: $-($ seronegative $)=\mathrm{S} / \mathrm{P}$ ratio $<0.45,+($ moderately seropositive $)=$ $\mathrm{S} / \mathrm{P}$ ratio $\geq 0.45$ and $<0.70$, and ++ (strongly seropositive) $=\mathrm{S} / \mathrm{P}$ ratio $\geq 0.70$. 
Table 6. Conversion of serological status among the 3 ELISA S/P (sample-to-positive) categories when the cows had repeated records in the years of 1998 and $2000 .^{1}$

\begin{tabular}{lrrrr}
\hline & \multicolumn{3}{c}{2000} & \\
\cline { 2 - 4 } 1998 & - & + & ++ & Total \\
\hline- & 323 & 25 & 2 & 350 \\
+ & 40 & 9 & 6 & 55 \\
++ & 13 & 2 & 11 & 26 \\
Total & 376 & 36 & 19 & 431 \\
\hline
\end{tabular}

${ }^{1}$ Categories were classified in terms of the ELISA S/P ratio. Category: $-($ seronegative $)=\mathrm{S} / \mathrm{P}$ ratio $<0.45,+($ moderately seropositive $)=$ $\mathrm{S} / \mathrm{P}$ ratio $\geq 0.45$ and $<0.70$, and ++ (strongly seropositive) $=\mathrm{S} / \mathrm{P}$ ratio $\geq 0.70$.

ner in which samples were collected in the work described here, seronegative conversion of daughters could account for the relatively low detected rate of vertical transmission. Because it is generally assumed that cattle remain permanently infected with $N$. caninum, these data suggest that some of the animals defined as seronegative were in fact false negatives. However, at present, it is not possible to identify such animals antemortem. If antemortem diagnostic tests are developed that allow identification of these animals, it would be important to include them in future genetic analyses, as they probably represent a population of animals with a superior ability to control $N$. caninum infection.

\section{Estimation of the Variance Components}

Heritability of susceptibility to $N$. caninum was estimated first using a simple sire model because this model permitted analysis of infection status either as a categorical variable or as a continuous variable. The sire variance from the categorical analysis was $0.023 \pm 0.012$ on the probit scale, with residual variance fixed at 1 , and heritability was $0.090 \pm 0.047$. When the log transformed ELISA data were used, the estimated heritability by the same sire model was $0.115 \pm 0.036$ (Table

Table 7. The Neospora caninum serological status of 3109 dams and their daughters $>6$ mo of age using 2 ELISA S/P (sample-to-positive) cut-off points.

\begin{tabular}{llrlr}
\hline & & \multicolumn{2}{c}{ Daughter } & \\
\cline { 3 - 4 } Cut-off & Dam & Seronegative & Seropositive & Total \\
\hline \multirow{4}{*}{$\geq 0.45$} & Seronegative & 2323 & 167 & 2490 \\
& Seropositive & 367 & 252 & 619 \\
& Total & 2690 & 419 & 3109 \\
& Seronegative & 2694 & 108 & 2802 \\
& Seropositive & 169 & 138 & 307 \\
\hline 0.70 & Total & 2863 & 246 & 3109 \\
\hline
\end{tabular}

8). Expression of serological status in just 2 categories (infected or not infected) appeared to capture most, but not all, of the genetic information in the ELISA S/P ratios. Subsequent analyses were all based on the logtransformed ELISA S/P ratios.

The estimated (co)variances, the heritability of susceptibility to $N$. caninum, and the model selection criteria $\left(\mathrm{MSE}_{\mathrm{c}}, \mathrm{MSE}_{\mathrm{d}}\right.$, and $\left.\mathrm{AIC}\right)$ for 5 genetic models are shown in Table 8 . The estimated heritabilities by SM, AM, SGM, SDM, and AMM were 0.115, 0.084, 0.124, 0.103 , and 0.301 , respectively. The total heritability estimated with the animal maternal effect model was considerably higher than with the other 4 models, because the estimated maternal variance was remarkably higher than the animal direct genetic variance. The large proportion of the maternal variance by the animal maternal effect model confirms that maternal environment plays an important role in the transmission of $N$. caninum. However, it is possible that the effect of $N$. caninum infection in a dam would be confounded with the estimates of the direct genetic and maternal genetic effects because $N$. caninum infection in a dam might affect the dam's performance. If that was the case, this would bias the estimates of both effects. However, on many farms it does not appear that $N$. caninum has a significant impact on production (Cramer et al., 2002; Hobson et al., 2002).

Collectively, the results suggest that the maternal permanent effect is a major factor influencing the high vertical transmission rate of $N$. caninum, since the heritability of direct genetic effects estimated by all models was small (8 to $12.4 \%$ ). As a result, management practices (prevention, culling of infected cows, etc.) should be more effective for controlling $N$. caninum infection than genetic selection.

Finally, the fit of the 5 models was compared based on 3 different criteria in Table 8. A model with a smaller $\mathrm{MSE}_{\mathrm{c}}, \mathrm{MSE}_{\mathrm{d}}$, or AIC was considered a better fit for the data. The models ranked consistently with the 3 different criteria. The fit of the sire-dam model was slightly better than that of the animal-maternal-effect model, but the differences were small. Both of these models were clearly superior to the remaining 3 , especially for the 2 criteria measured on all the data $\left(\mathrm{MSE}_{\mathrm{c}}\right.$ and AIC). Accounting for maternal variation when modeling $N$. caninum infection status was essential.

\section{CONCLUSIONS}

The overall mean seroprevalence of $N$. caninum in the selected Ontario Holstein herds was $11.2 \%$, with a median of $7.1 \%$, and varied from 0 to $70.4 \%$ in different herds over the 3 yr of the study. The apparent efficiency of vertical transmission of $N$. caninum in the selected 
Table 8. Estimates of (co)variance components and heritability (SE in parentheses) of susceptibility to Neospora caninum and model selection criteria $\left(\mathrm{MSE}_{\mathrm{c}}, \mathrm{MSE}_{\mathrm{d}} \text {, and } \mathrm{AIC}\right)^{1}$ by a sire model (SM), an animal model (AM), a sire-maternal grandsire model (SGM), a sire-dam model (SDM), and an animal maternal effect model (AMM), with the transformed ELISA data.

\begin{tabular}{|c|c|c|c|c|c|}
\hline Parameters & SM & $\mathrm{AM}$ & SGM & $\mathrm{SDM}$ & $\mathrm{AMM}$ \\
\hline $\begin{array}{l}\sigma_{\mathrm{s}}^{2} \\
\sigma_{\mathrm{g}}^{2}\end{array}$ & $0.0073(0.0023)$ & & $\begin{array}{l}0.0079(0.0039) \\
0.0021(0.0019)\end{array}$ & $0.0068(0.0031)$ & \\
\hline $\begin{array}{l}\sigma^{2^{5}} \\
\sigma_{\mathrm{a}}^{2}\end{array}$ & & $0.0219(0.0080)$ & & $0.1020(0.0017)$ & $\begin{array}{l}0.0251(0.0094) \\
0.0689(0.0019)\end{array}$ \\
\hline $\begin{array}{l}\sigma_{\mathrm{am}} \\
\sigma_{\mathrm{e}}^{2}\end{array}$ & $0.2473(0.0040)$ & $0.2375(0.0050)$ & $0.2439(0.0036)$ & $0.1543(0.0072)$ & $\begin{array}{l}0.0142(0.0032) \\
0.1601(0.0058)\end{array}$ \\
\hline $\begin{array}{l}\sigma^{2}{ }^{\mathrm{e}} \\
\mathrm{h}^{{ }^{2}}{ }^{2} \\
\mathrm{~h}^{2}{ }_{\mathrm{m}}\end{array}$ & $0.2546(0.0652)$ & $0.2594(0.0672)$ & $0.2539(0.0636)$ & $0.2631(0.0702)$ & $\begin{array}{l}0.2683(0.0705) \\
0.094(0.044) \\
0.257(0.089)\end{array}$ \\
\hline$h^{2}{ }_{T}^{m}$ & $0.115(0.036)$ & $0.084(0.042)$ & $0.124(0.032)$ & $0.103(0.025)$ & $0.301(0.061)$ \\
\hline $\mathrm{MSE}_{\mathrm{c}}$ & 0.2429 & 0.2307 & 0.2259 & 0.1051 & 0.1085 \\
\hline $\mathrm{AIC}$ & $-11,354$ & $-11,768$ & $-11,935$ & $-18,077$ & $-17,823$ \\
\hline $\mathrm{MSE}_{\mathrm{d}}$ & 0.2404 & 0.2316 & 0.2286 & 0.2186 & 0.2198 \\
\hline
\end{tabular}

${ }^{1} \mathrm{MSE}_{\mathrm{c}}=$ Mean square error with complete data set, $\mathrm{MSE}_{\mathrm{d}}=$ mean square error with partially deleted $(30 \%)$ data set, AIC $=$ Akaike information criterion (Akaike, 1973).

herds was $40.7 \%$. The N. caninum seropositive conversion rate of cows over 6 mo of age for the 2 -yr period of the study was between 3.98 and $7.71 \%$, whereas the $N$. caninum seronegative conversion rate was between 28.24 and $65.43 \%$. The estimated heritability of susceptibility to $N$. caninum using 5 models was between 0.084 and 0.301 with logarithmic-transformed ELISA data, and the estimated heritability using a sire model and the binary serological status (seropositive and seronegative) was 0.090. Direct and maternal heritabilities estimated by maternal effects mode were 0.094 and 0.257 , respectively. The sire-dam model and the animal maternal effect model fit the data better than other models. Maternal effect accounted for a greater variation in susceptibility to $N$. caninum than direct genetic effect, suggesting that management practices are more important than genetic selection in reducing the incidence of this parasite.

\section{ACKNOWLEDGMENTS}

The funding for this project was provided by the Dairy Farmers of Ontario, the Matching Investment Initiative of Agriculture and Agri-Food Canada, Ontario Ministry of Agriculture, Food and Rural Affairs, and the Natural Sciences and Engineering Research Council of Canada. The technical assistance of Gerard Cramer, Mark Cochran, Jamie Hobson, Greg Wideman, and Alec Smith is greatly acknowledged here.

\section{REFERENCES}

Akaike, H. 1973. Information theory and an extension of the maximum likelihood principle. Pages 267-281 in Second International Symposium on Information Theory. B. N. Petrov and F. Csaki, ed. Academiai Kiado, Budapest, Hungary.

Anderson, M. L., P. C. Blanchard, B. C. Barr, J. P. Dubey, R. L. Hoffman, and P. A. Conrad. 1991. Neospora-like protozoan infec- tion as a major cause of abortion in California dairy cattle. JAVMA 198:241-244.

Anderson, M. L., C. W. Palmer, M. C. Thurmond, J. P. Picanso, P. C. Blanchard, R. E. Breitmeyer, A. W. Layton, M. McAllister, B. Daft, and H. Kinde. 1995. Evaluation of abortions in cattle attributable to neosporosis in selected dairy herds in California. JAVMA 207:1206-1210.

Atkinson, R. A., R. W. Cook, L. A. Reddacliff, J. Rothwell, K. W. Broady, P. Harper, and J. T. Ellis. 2000. Seroprevalence of Neospora caninum infection following an abortion outbreak in a dairy cattle herd. Aust. Vet. J. 78:262-266.

Bergeron, N., G. Fecteau, J. Paré, R. Martineau, and A. Villeneuve. 2000. Vertical and horizontal transmission of Neospora caninum in dairy herds in Quebec. Can. Vet. J. 41:464-467.

Boulton, J. G., P. A. Gill, R. W. Cook, G. C. Fraser, P. A. Harper, and J. P. Dubey. 1995. Bovine Neospora abortion in north-eastern New South Wales. Aust. Vet. J. 72:119-120.

Corbellini, L. G., D. Driemeier, C. F. E. Cruz, L. F. P. Gondim, and V. Wald. 2002. Neosporosis as a cause of abortion in dairy cattle in Rio Grande do Sul, southern Brazil. Vet. Parasitol. 103:195-202.

Cramer, G., D. Kelton, T. F. Duffield, J. C. Hobson, K. Lissemore, S. K. Hietala, and A. S. Peregrine. 2002. Neospora caninum serostatus and culling of Holstein cattle. JAVMA 221:1165-1168.

Davison, H. C., A. Otter, and A. J. Trees. 1999. Estimation of vertical and horizontal transmission parameters of Neospora caninum infections in dairy cattle. Int. J. Parasitol. 29:1683-1689.

Dubey, J. P., A. L. Hattel, D. S. Lindsay, and M. J. Topper. 1988. Neonatal Neospora caninum infection in dogs: Isolation of the causative agent and experimental transmission. JAVMA 193:1259-1263.

Dubey, J. P., and D. S. Lindsay. 1996. A review of Neospora caninum and neosporosis. Vet. Parasitol. 67:1-59.

Dyer, R. M., M. C. Jenkins, O. C. Kwok, L. W. Douglas, and J. P. Dubey. 2000. Serologic survey of Neospora caninum infection in a closed dairy cattle herd in Maryland: Risk of serologic reactivity by production groups. Vet. Parasitol. 90:171-181.

Gilmour, A. R., B. R. Cullis, S. J. Welham, and R. Thompson. 2001. ASREML Reference Manual. NSW Agriculture, Orange Agricultural Institute, Forest Road, Orange, 2800, Australia.

Hobson, J. C. 2003. A case-control seroepidemiological investigation of Neospora caninum in Ontario dairy herds. M. Sc. Thesis, University of Guelph, Canada.

Hobson, J. C., T. F. Duffield, D. Kelton, K. Lissemore, S. K. Hietala, K. E. Leslie, B. McEwen, G. Cramer, and A. S. Peregrine. 2002. Neospora caninum serostatus and milk production of Holstein cattle. JAVMA 221:1160-1164.

McEwen, B., M. Hazlett, M. Archambault, S. Carman, and D. Alves. 2001. Bovine abortion update, 1993-2001. Anim. Health Lab. Newsl., University of Guelph 5:5-7. 
Moen, A. R., W. Wouda, M. F. Mul, E. A. Graat, and T. van Werven. 1998. Increased risk of abortion following Neospora caninum abortion outbreaks: A retrospective and prospective cohort study in four dairy herds. Theriogenology 49:1301-1309.

Paré, J., S. K. Hietala, and M. C. Thurmond. 1995. An enzymelinked immunosorbent assay (ELISA) for serological diagnosis of Neospora sp. infection in cattle. J. Vet. Diagn. Invest. 7:352-359.

Paré, J., M. C. Thurmond, and S. K. Hietala. 1996. Congenital Neospora caninum infection in dairy cattle and associated calfhood mortality. Can. J. Vet. Res. 60:133-139.

Paré, J., M. C. Thurmond, and S. K. Hietala. 1997. Neospora caninum antibodies in cows during pregnancy as a predictor of congenital infection and abortion. J. Parasitol. 83:82-87.

SAS/STAS User's Guide, Version 6, Fourth Edition, Volume 2. 1990. SAS Inst., Inc., Cary, NC.
Thurmond, M. C., and S. K. Hietala. 1996. Culling associated with Neospora caninum infection in dairy cows. Am. J. Vet. Res. 57:1559-1562.

Thurmond, M. C., and S. K. Hietala. 1997. Effect of Neospora caninum infection on milk production in first-lactation dairy cows. JAVMA 210:672-674

Varona, L., I. Misztal, and J. K. Bertrand. 1999. Threshold-linear versus linear-linear analysis of birth weight and calving ease using an animal model: II. Comparison of models. J. Anim. Sci. 77:2003-2007.

Waldner, C. L., J. Henderson, J. T. Wu, K. Breker, and E. Y. Chow. 2001. Reproductive performance of a cow-calf herd following a Neospora caninum-associated abortion epidemic. Can. Vet. J. 42:355-360.

Willham, R. L. 1972. The role of maternal effects in animal breeding: III. Biometrical aspects of maternal effects in animals. J. Anim. Sci. 35:1288-1293. 